\title{
Selection and Characterization of the Virulent Fusarium oxysporum f. sp. lycopersici Isolate Inciting Vascular Wilt of Tomato
}

\author{
V. Kavi Sidharthan, Rashmi Aggarwal, N. Surenthiran and V. Shanmugam* \\ Division of Plant Pathology, ICAR-Indian Agricultural Research Institute, \\ New Delhi-110012, India \\ *Corresponding author
}

\section{A B S T R A C T}

\begin{tabular}{|l|}
\hline K e y w o r d s \\
$\begin{array}{l}\text { Fusarium, Tomato, } \\
\text { Fusarium oxysporum } \\
\text { f.sp. lycopersici, } \\
\text { Characterization }\end{array}$ \\
\hline Article Info \\
\hline $\begin{array}{l}\text { Accepted: } \\
\text { 17 January } 2018 \\
\text { Available Online: } \\
\text { 10 February } 2018\end{array}$ \\
\hline
\end{tabular}

\section{Introduction}

Vegetables serve as the rich sources of vitamins and nutrients thereby playing an important role in the balanced diet of human beings. Among the vegetables, Solanum lycopersicum $\mathrm{L}$., the cultivated tomato is the second most consumed vegetable crop next to potato (Srivastava et al., 2010). Tomato is susceptible to several biotic stresses that greatly limit its production and productivity. Major foliar diseases are gray mold (Botrytis cinerea), Cercospora leaf mold (Cercospora fuligena), early blight (Alternaria solani), bacterial canker (Clavibacter michiganensis) and tomato leaf curl disease (Tomato leaf curl
Fusarium oxysporum f. sp. lycopersici [FOL], the pathogen inflicting vascular wilt in tomato, pose a serious threat to the nutritional security. In India, due to lack of proper knowledge on the disease aetiology, the management of the disease becomes difficult. The main objective of this study is to select the most virulent FOL isolate among 7 putative Fusarium isolates, including 2 isolates acquired during field survey. The pathogenicity plants within 5 days of pathogen inoculation. Based on morphological, partholical, and sequence analyses of the ITS region, and by fulfiling Koch's postulates, this isolate was characterized as Fusarium oxysporum f.sp. lycopersici. This selected isolate can be used in further studies for developing management strategies against FOL. virus) (Reddy et al., 2005). The main soil borne diseases include Fusarium wilt (Fusarium oxysporum f.sp. lycopersici), bacterial wilt (Ralstonia solanacearum), late blight (Phytophthora infestans), damping off (Pythium aphanidermatum) (Schwarz and Grosch, 2003) and Verticillium wilt (Verticillium albo-atrum) (Schaible et al., 1951). Among these, Fusarium oxyporum f.sp. lycopersici [FOL] (Sacc.) W.C.Synder and H.N. Hans, incident of vascular wilt of tomato, alone causes $30-40 \%$ yield loss and in India, under adverse weather conditions, the losses may reach as high as $80 \%$ (Nirmaladevi et al., 2016). FOL exists as hemi-biotroph and is closely related to biotrophs than necrotrophs 
owing to its biotrophic lifestyle during the initial stages of plant roots invasion (Francia et al., 2007). Although a range of solanaceous crops and weed species are reported to be the symptomless carriers of FOL, tomato is generally regarded as the primary host of FOL (Mc Govern, 2015). In tomato seedlings, FOL causes damping off characterized by yellowing, stunting and wilting. In mature tomato plants, the wilt symptoms include foliar yellowing and wilting which is more evident after flowering and fruit set especially in the hottest day time. Due to the invasion and blockage of distinct sectors of the vascular tissue, the wilt symptoms can show one sided appearance. Vascular discolouration becomes prominent and extends up to the entire stem length sometimes into the petiolar vascular tissue. Symptoms of FOL can be exacerbated by warmer temperatures of approximately $28^{\circ} \mathrm{C}$, lower soil $\mathrm{pH}$ and the use of ammonium based nitrogen fertilizers (Mc Govern, 2015). Recently, in assessing the aetiology of the disease, besides $F$. oxysporum, the associations of $F$. solani in exhibiting characteristic vascular wilt symptoms in both Himachal Pradesh and Delhi regions were reported (Shanmugam et al., 2017). This warrants a detailed characterization of the pathogen which will help us in formulating suitable management strategies. In this regard, the current work aims at selecting the most virulent Fusarium isolate and its characterization, which can later be used for evaluation of various management practices.

\section{Materials and Methods}

\section{Fungal isolates}

Field surveys were conducted in the tomato fields of IARI Farm during 2016-2017 and Fusarium infected plant samples were collected from each of the locations. The fungal pathogen was isolated from the infected tissues by employing standard isolation methods (Riker and Riker, 1936). The infected tissues were cut into small pieces and surface sterilized with $2 \%$ sodium hypochlorite for 30 s. They were then washed in three changes of sterile distilled water and dried between two layers of blotting papers. The bits were further plated on Potato Dextrose Agar (PDA) medium containing $100 \mathrm{ppm}$ streptomycin in sterile Petri dishes and incubated at room temperature $\left(28 \pm 2^{\circ} \mathrm{C}\right)$. The fungal growth appearing around the bits were sub-cultured on plates containing PDA. These isolates together with other available putative Fusarium isolates in the laboratory culture collections (Table 1) obtained from vascular wilt infected tomato were subjected to morphological characterization and pathogenicity assay.

\section{Morphological characterization}

Monoconidial culture of Fusarium isolates were obtained through single spore isolation technique (Riker and Riker, 1936). To study the morphological characteristics, a portion of actively growing culture discs of the fungus from PDA was picked up with a sterile needle and teased out in a drop of water placed on a microscopic slide. The slide was covered with a clean cover slip taking care to exclude air bubbles. The morphological characters of the fungus were studied using LMI BM light microscope with maximum possible magnification (40x) (Fig. 2).

\section{Pathogenicity assay}

The pathogenicity of the fungal isolates was established in a polyhouse under artificial inoculated conditions by root inoculation. The fungal inoculum was obtained from a 7-day old culture on PDA medium. From each Petri plate, the conidial suspension was prepared using $20 \mathrm{ml}$ of sterile distilled water. The bigger mycelial parts were removed by filtering the suspension through a fine nylon mesh. After quantifying the suspension in a hemocytometer, the conidial concentration 
was adjusted to $10^{4}$ spores $/ \mathrm{ml}$ using sterile distilled water and used as an inoculum after mixing with $0.05 \%$ Tween 80 . Apparently healthy seedlings of 25-days old tomato plants (cv. Pusa Rohini) grown under controlled conditions were used for the inoculation. The roots were injured and dipped in the conidial suspension for 3 hours followed by transplanting of inoculated seedlings in sterilized potting mixture. Seedlings inoculated with sterile distilled water served as the control. Four seedlings were used for each isolate as replicates. Disease incidence was recorded after 7 days post pathogen inoculation. The pathogen was re-isolated from the collar region of artificially inoculated plants to confirm Koch's postulates. A highly virulent isolate was selected and molecular characterization was carried out.

\section{DNA extraction}

The identity of the virulent pathogen isolate was characterized by PCR amplification of ITS region from the genomic DNA as follows. Five day old submerged culture mycelium, grown in PDB and incubated at $28 \pm 2{ }^{\circ} \mathrm{C}$ and $180 \mathrm{rpm}$ for 5 days, was used for DNA isolation. In submerged culture, individual colonies of each of the fungal isolates grown on PDA plates were inoculated separately in $100 \mathrm{ml}$ of PDB. The inoculated flasks were incubated on a rotary shaker.

The mycelium was filtered out on a sterile Whatman No. 1 filter paper and washed thrice with sterile distilled water to remove traces of the medium. After air drying, the fungal mass was frozen immediately in liquid nitrogen ($\left.196{ }^{\circ} \mathrm{C}\right)$. The dried mats were ground with a mortar and pestle in liquid nitrogen and genomic DNA was isolated following the standard procedure with some modifications (Saghai-Maroof et al., 1984).

Molecular characterization
To characterize the pathogen isolates, a region of the nuclear rRNA gene containing the ITS regions 1 and 2 and the 5.8s rRNA gene was amplified from the genomic DNA by PCR using the primer combinations ITS1 (5, TCCGTAGGTGAACCTGCGG 3') and ITS4 (5' TCCTCCGCTTATTGATATGC 3') to get an amplicon size of 500-550 bp (White et al., 1990). Amplifications were carried out in 50 $\mu 1$ reaction volume consisting of $10 \mathrm{X}$ buffer, $5.0 \mu \mathrm{l} ; 2 \mathrm{mM}$ dNTPs, $2.0 \mu \mathrm{l} ; 3 \mathrm{U} / \mu \mathrm{l}$ Taq DNA polymerase, $1.0 \mu \mathrm{l} ; 100 \mathrm{ng} / \mu \mathrm{l}$ of each primer, $2 \mu \mathrm{l}$; 50-100 ng template DNA, $3 \mu \mathrm{l}$ and $\mathrm{H}_{2} \mathrm{O}$ $32.0 \mu \mathrm{l}$ in a Biorad thermalcycler using the PCR conditions $94{ }^{\circ} \mathrm{C}$ for $4 \mathrm{~min}$ (initial denaturation), $94{ }^{\circ} \mathrm{C}$ for $1 \mathrm{~min}$ (denaturation), $55^{\circ} \mathrm{C}$ for $1 \mathrm{~min}$ (annealing) and $72{ }^{\circ} \mathrm{C}$ for 2 min (extension).

The total number of cycles was 35 , with the final extension of $72^{\circ} \mathrm{C}$ for $10 \mathrm{~min}$. The amplified products $(50 \mu \mathrm{l})$ were size separated on $1.2 \%$ agarose gel. The PCR products were purified, ligated with pGEM-T easy vector (Promega) by following manufacturer's protocol and transformed into competent Escherichia coli strain DH5a (Fig. 4).

The transformed cells were inoculated in Luria Bertani broth and from the overnight grown culture, plasmid isolation was carried out by using Promega plasmid miniprep system.

\section{Sequencing, homology and phylogenetic analysis}

About $100 \mathrm{ng}$ of plasmid (double stranded) DNA was used as template for sequencing PCR. A sequence similarity search was done using GenBank BLASTN of National Center for Biotechnology Information (NCBI). Sequences of closely related taxa were retrieved and phylogenetic analysis was performed using MEGA5.0 software.

Fig.1 Cultural characteristics of the putative Fusarium isolates used in this study 


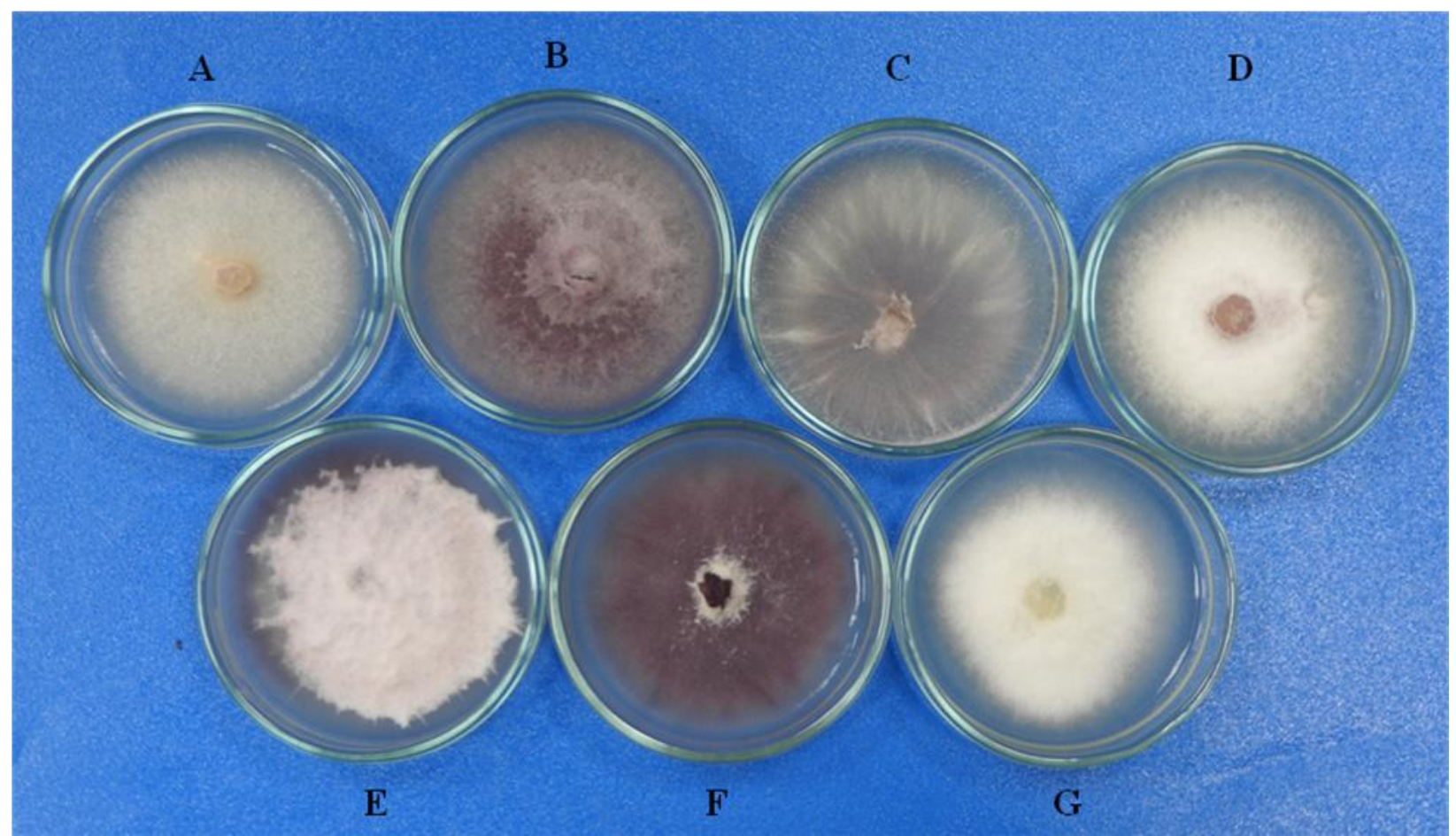

A. TOFU-MM, B. TOFU-CPCT-2, C. TOFU-IHBT, D. TOFU-CPCT-3, E. TOFU-4-TISSA, F. TOXX-POT-1, G. TOFOL-CBE

Fig.2 Conidial characteristics of the putative Fusarium isolates
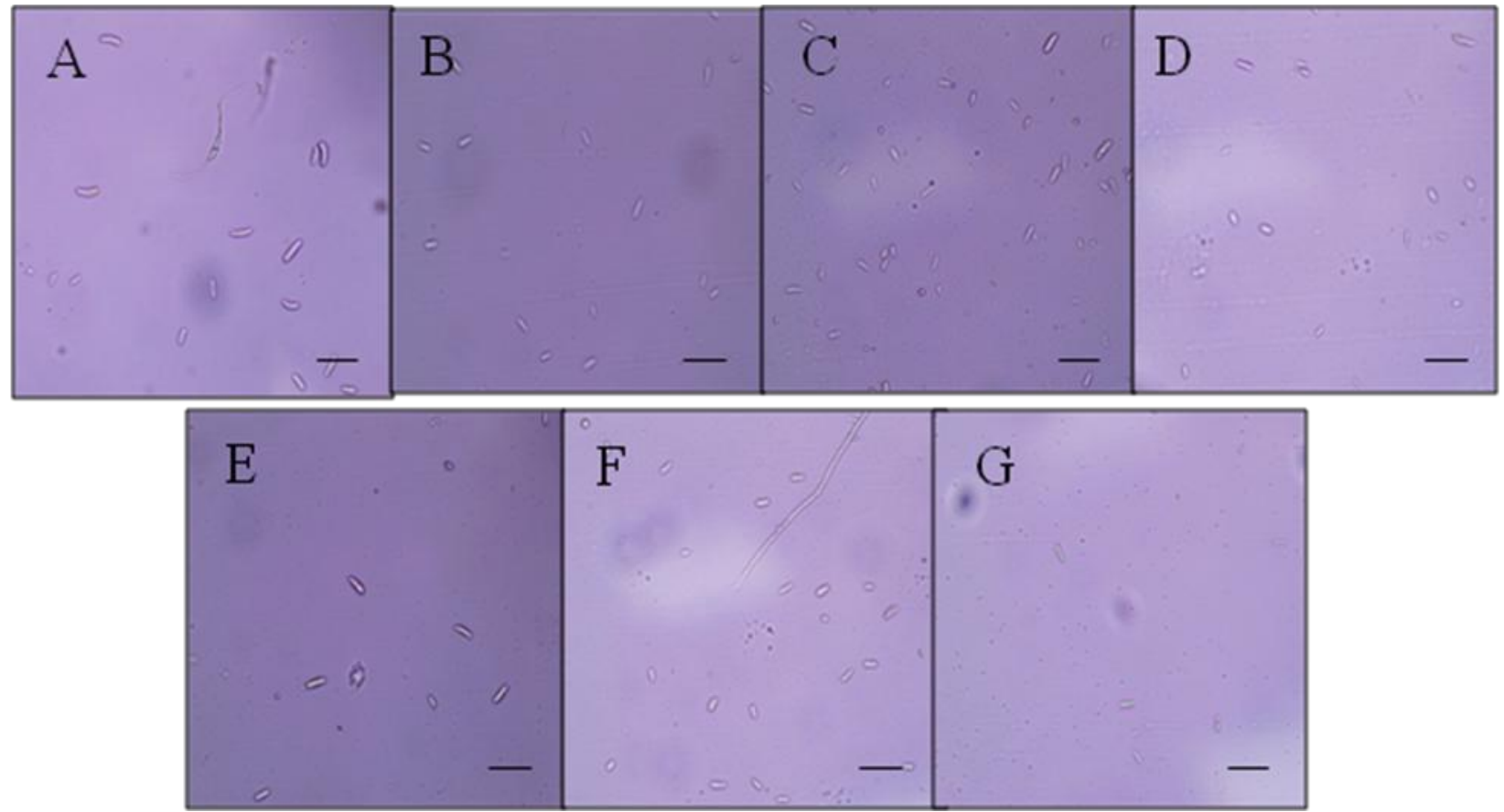

A. TOFOL-CBE, B. TOFU-TISSA-4, C. TOFU-IHBT, D. TOFU-CPCT-3, E. TOFU-MM, F. TOXX-POT-1, G. TOFU-CPCT-2.

Fig.3 Pathogenicity of the putative Fusarium isolates of tomato on 25 day old tomato cv. Pusa 


\section{Rohini}

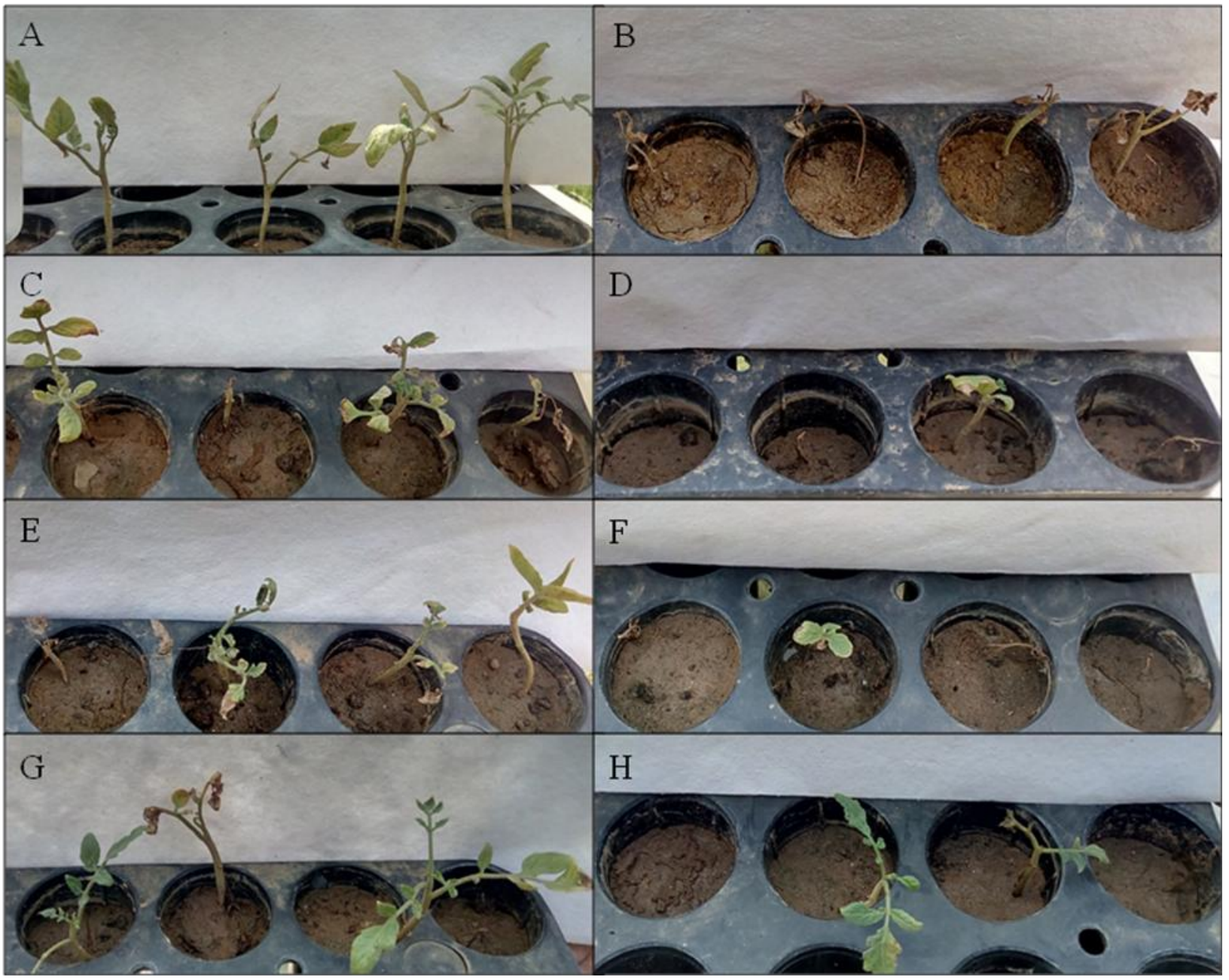

A. Non pathogenic control, B. TOFU-IHBT, C. TOFU-MM, D. TOFU-CPCT-3, E. TOXX-POT-1, F. TOFU-TISSA -4, G. TOFOL-CBE, H. TOFU-CPCT-2

Fig.4 PCR amplification of ITS region of the highly virulent Fusarium isolate TOFU-IHBT. Lanes 1-100 bp ladder, 2-PCR product

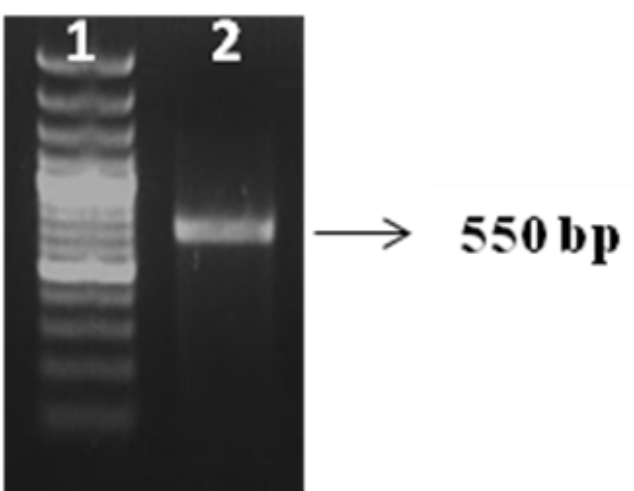

Fig.5 Phylogenetic tree based on ITS sequences, drawn using the neighbor joining method and 
showing the relation of the most virulent Fusarium isolate, TOFU-IHBT with other Fusarium isolates. The isolate name is given after the GenBank accession numbers of each species. Bar, 0.02 substitution per site

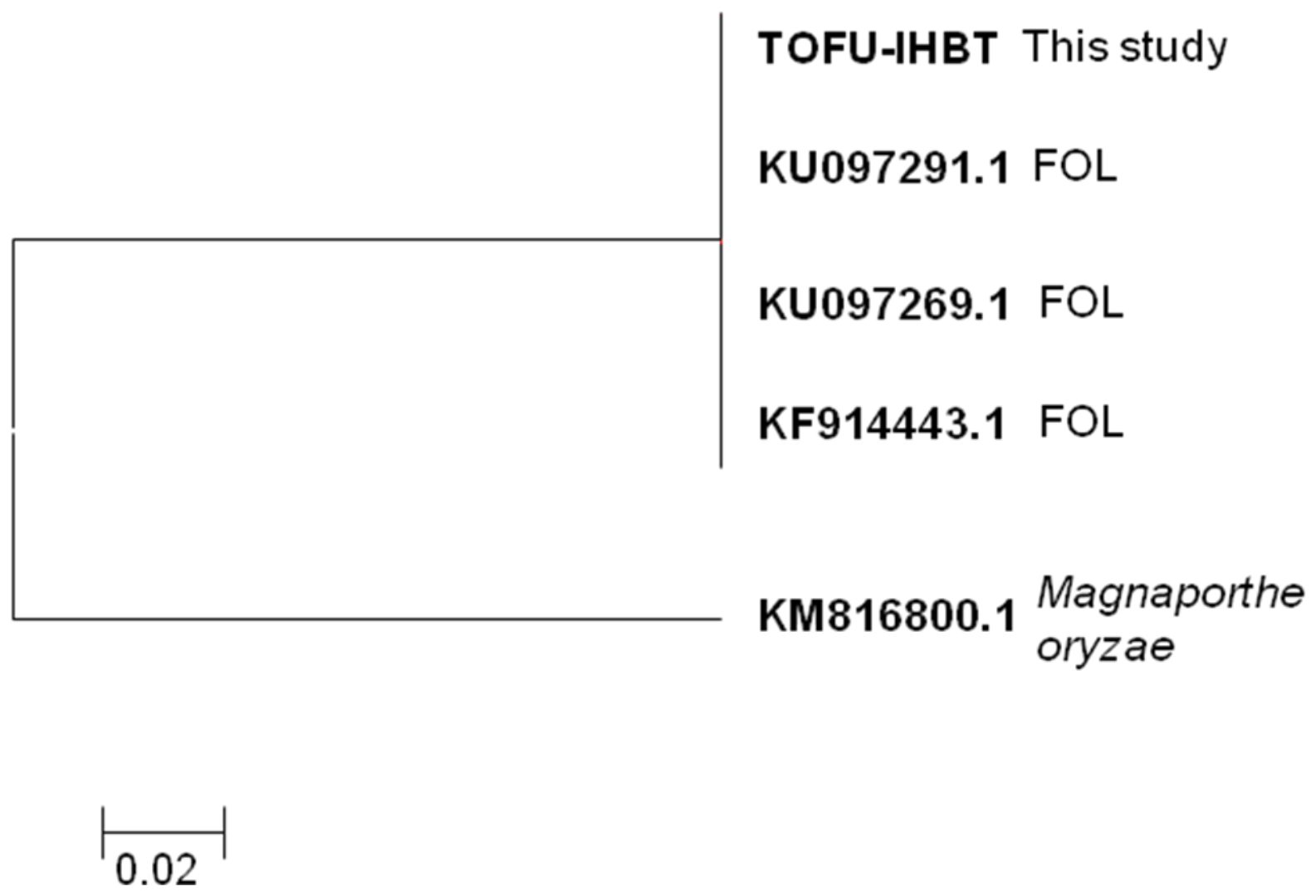

Table.1 List of putative Fusarium isolates of tomato used in this study

\begin{tabular}{|l|l|l|l|}
\hline S. No. & \multicolumn{1}{|c|}{ Code } & \multicolumn{1}{|c|}{ Location } & \multicolumn{1}{|c|}{ Mode of Acquisition } \\
\hline $\mathbf{1}$ & TOFU-IHBT & Barmat, Himachal Pradesh & Laboratory collection \\
\hline $\mathbf{2}$ & TOXX- POT-1 & Rajpur, Himachal Pradesh & Laboratory collection \\
\hline $\mathbf{3}$ & TOFU-TISSA -4 & Tissa, Himachal Pradesh & Laboratory collection \\
\hline $\mathbf{4}$ & TOFOL-CBE & Coimbatore, Tamil Nadu & Laboratory collection \\
\hline $\mathbf{5}$ & TOFU-MM & MM, Himachal Pradesh & Laboratory collection \\
\hline $\mathbf{6}$ & TOFU-CPCT-2 & CPCT, New Delhi & Field survey \\
\hline $\mathbf{7}$ & TOFU-CPCT-3 & VRF, New Delhi & Field survey \\
\hline
\end{tabular}


Table.2 Colony diameter and wilt incidence exhibited by different Fusarium isolates

\begin{tabular}{|l|c|c|}
\hline Isolate & Colony diameter $(\mathrm{mm})$ & $\begin{array}{c}\text { Percent disease } \\
\text { incidence }^{\#}\end{array}$ \\
\hline TOFU-IHBT & $4.00^{\mathrm{a}}$ & $100.00^{\mathrm{a}}$ \\
\hline TOXX-POT1 & $3.80^{\mathrm{a}}$ & $81.25^{\mathrm{d}}$ \\
\hline TOFU-TISSA-4 & $3.17^{\mathrm{b}}$ & $93.75^{\mathrm{b}}$ \\
\hline TOFOL-CBE & $3.63^{\mathrm{a}}$ & $81.25^{\mathrm{d}}$ \\
\hline TOFU-MM & $3.10^{\mathrm{b}}$ & $81.25^{\mathrm{d}}$ \\
\hline TOFU-CPCT-2 & $3.96^{\mathrm{a}}$ & $87.50^{\mathrm{c}}$ \\
\hline TOFU-CPCT-3 & $3.67^{\mathrm{a}}$ & $93.75^{\mathrm{b}}$ \\
\hline
\end{tabular}

"Values are mean of three replications; colony diameter was measured after 5 days of pathogen inoculation when one of the isolates covered the full $40 \mathrm{~mm}$ diameter glass plate; "Values are mean of four replications; disease incidence was measured after 7 days post pathogen inoculation; Means followed by a common letter are not significantly different at $5 \%$ level by DMRT.

\section{Statistical analysis}

The data were statistically analyzed using Web Agri Stat Package 2.0 and Duncan's Multiple Range Test (DMRT) was used to compare the treatment means.

\section{Results and Discussion}

Vascular wilt of tomato was widely prevalent to the extent of $10-15 \%$ in IARI farms. On isolation of the associated pathogen from vascular tissues of infected stems on potato dextrose agar, both samples from two fields revealed a single type of fungus. On PDA plates, all the putative Fusarium isolates, including the two isolates obtained during field survey, demonstrated various colony characteristics ranging from fluffy mycelium to immersed mycelium (Fig. 1). Considering growth pattern, TOFU-IHBT covered the full $40 \mathrm{~mm}$ diameter petriplate within 5 days of inoculation while TOFU-MM demonstrated the lowest growth of only $31 \mathrm{~mm}$ (Table 2). In some isolates like TOFU-CPCT-2, TOFU4-TISSA and TOXX-POT-1, pink pigmentation was more evident than in others. In pathogenicity assays, one isolate designated as TOFU-IHBT, representing Himachal Pradesh, that exhibited systemic infection within 5 days and caused mortality of all the four seedlings, was identified as a highly virulent isolate and used for further characterization (Fig. 3, Table 2). PCR amplification of Internal Transcribed Spacer (ITS) region of the strain TOFU-IHBT yielded 550bp amplicons. In establishing the identity of the strain TOFU-IHBT, by sequencing of its Internal Transcribed Spacer (ITS) region, its sequence displayed 100\% identity to the sequences of $F$. oxysporum f.sp. lycopersici isolates with Accession No KU097291.1, KU097269.1 and KF914443.1, available in the NCBI database. In phylogenetic analysis, the ITS sequences of TOFU-IHBT was grouped along with other isolates of $F$. oxysporum as a single cluster (Fig. 5). Thus, based on colony morphology, sequence of the ITS region, and Koch's postulates, the highly pathogenic strain, TOFU-IHBT was identified as $F$. oxysporum f.sp. lycopersici. Future researches can be directed to determine the role of environmental parameters in disease causation by various Fusarium isolates. Also, molecular mechanisms underlying the differences in virulence need to be explored in detail. The identified isolate, TOFU-IHBT can now be used for developing and evaluating various management strategies 
including screening of tomato genotypes for Fusarium wilt resistance and evaluating the efficacy of fungicides and biocontrol control agents in managing Fusarium wilt of tomato.

\section{Acknowledgements}

The authors are grateful to the Director, ICAR-Indian Agricultural Research Institute and Head, Division of Plant Pathology, for providing facilities for our research work.

\section{References}

Francia, D., Demaria, D., Calderini, O., Ferraris, L., Valentino, D., Arcioni, S. and Cardinale, F. 2007. Wounding induces resistance to pathogens with different lifestyles in tomato: role of ethylene in cross protection. Plant Cell Environ., 30(11): 1357-1365.

McGovern, R. J. 2015. Management of tomato diseases caused by Fusarium oxysporum. Crop Prot., 73: 78-92.

Nirmaladevi, D., Venkataramana, M., Srivastava, R. K., Uppalapati, S. R., Gupta, V. K., Yli-Mattila, T. and Chandra, N. S. 2016. Molecular phylogeny, pathogenicity and toxigenicity of Fusarium oxysporum f.sp. lycopersici. Sci. Rep., 6: 21367.

Reddy, R. C., Colvin, J., Muniyappa, V. and Seal, S. (2005). Diversity and distribution of begomoviruses infecting tomato in India. Arch. Virol., 150(5): 845-867.

Saghai-Maroof, M. A., Soliman, K. M., Jorgensen, R. A. and Allard, R. W. 1984. Ribosomal DNA spacer-length polymorphisms in barley: Mendelian inheritance, chromosomal location, and population dynamics. Proc. Natl. Acad. Sci., 81(24): 8014-8018.

Schaible, L., Cannon, O. S. and Waddoups, V. (1951). Inheritance of resistance to Verticillium wilt in a tomato cross. Phytopathology, 41(11): 986-990.

Schwarz, D. and Grosch, R. 2003. Influence of nutrient solution concentration and a root pathogen (Pythium aphanidermatum) on tomato root growth and morphology. Sci. Hortic., 97(2): 109-120.

Shanmugam, V., Sharma, V., Bharti, P., Jyoti, P., Yadav, S. K., Aggarwal, R. and Jain, S. 2017. RNAi induced silencing of pathogenicity genes of Fusarium spp. for vascular wilt management in tomato. Ann. Microbiol., 67(5): 359-369.

Srivastava, R., Khalid, A., Singh, U. S. and Sharma, A. K. 2010. Evaluation of arbuscular mycorrhizal fungus, fluorescent Pseudomonas and Trichoderma harzianum formulation against Fusarium oxysporum f.sp. lycopersici for the management of tomato wilt. Biol. control, 53(1): 24-31.

\section{How to cite this article:}

Kavi Sidharthan, V., Rashmi Aggarwal, N. Surenthiran and Shanmugam, V. 2018. Selection and Characterization of the Virulent Fusarium oxysporum f. sp. lycopersici Isolate Inciting Vascular Wilt of Tomato. Int.J.Curr.Microbiol.App.Sci. 7(02): 1749-1756. doi: https://doi.org/10.20546/ijcmas.2018.702.212 